\title{
La agonía de la carne desde Miguel de Unamuno
}

The agony of The Flesh from Miguel de Unamuno

Juan Granados-Valdéz*

* Universidad Autónoma de Querétaro, México

Correo-e: juan.granados@uaq.mx (iD https://orcid.org/-0003-0000 9055-4020

Recibido: 21 de febrero de 2019 Aprobado: 20 de mayo de 2019

Resumen: Se presenta una reflexión sobre la lucha del ser humano contra la muerte, lucha que en sí misma incluye tanto la fe como la duda. Con base en algunas obras de Miguel de Unamuno, especialmente La agonía del cristianismo, se analizan las concepciones judeocristianas y platónicas del alma y el cuerpo en relación con el ansia de infinitud del individuo - por medio de la paternidad, la historia, el recuerdo de los otros, la resurrección del cuerpo y la inmortalidad del alma-. Finalmente, se establece la agonía de la carne como principio y realidad fundamental del ser humano.

Palabras clave: filosofía; cristianismo; muerte; alma; cuerpo

Abstract: We present reflection on the struggle of human being against death is presented. A struggle that itself implies both faith and doubt. On the basis of some works by Miguel de Unamuno, especially The agony of Christianity, the Judeo-Christian and Platonic conceptions of body and soul are analyzed as regards the individual's yearning for infinitude - by means of paternity, history, memories of others, the resurrection of the body and immortality of the soul- Finally, the agony of the flesh is established as inception and fundamental reality of human beings.

Keywords: philosophy; Christianity; death; soul; body 
iÉste fue el ser humano, éste fue el padre, éste fue el cristiano en agonía del cristianismo! Miguel de Unamuno, La agonía del cristianismo

iYo no voy por vuestro camino, despreciadores del cuerpo! Federico Nietzsche, Así hablaba Zaratustra

Cuando el cuerpo está triste, el corazón languidece. Albert Camus, La caída

\section{INTRODUCCIÓN}

En las primeras líneas de la obra Del sentimiento trágico de la vida (2003), Unamuno se aleja decididamente del adjetivo 'humano' — Zadjetivo o apelativo? - y de toda su familia lingüística porque le parece sospechoso de complicidad de ese angelismo que nutre la filosofía y todas las consideraciones que del ser humano hay. Angelismo que hace del individuo un ente ajeno a sí mismo, extraño, desde el momento en el que lo escinde en alma y cuerpo, y privilegia el alma haciéndola, a ella, el ser humano mismo, desdeñando esa otra realidad que lo compone: el cuerpo. El que a Unamuno le importa, y a nosotros, es el individuo de carne y hueso (y vida) que llora, padece, sufre, se duele, ríe y ama, él mismo, tú y yo, cada uno, nosotros. El ser humano, en una palabra, que agoniza. El interés reciente por el cuerpo, tan marcado en nuestra época, no sólo justifica un estudio sobre la carne y su agonía, sino que, además, puede sumar ideas no tratadas a fin de vislumbrar cómo dicho interés no es sino una más de las agonías de la carne.

El propósito de este ensayo es mostrar que la agonía que caracteriza al ser humano concreto es propia del cuerpo, que se quiere a sí mismo vivo, carne viva, pero que encuentra en la muerte su más grande obstáculo para ver cumplido su deseo. En primer lugar se expone, siguiendo al mismo Unamuno, el concepto de agonía, resaltando por un lado lo que directamente tiene que ver con la carne y, por otro, la relación que guarda con el cristianismo. En segundo lugar, a modo de ejemplo o paradigma del ser humano agónico, se habla del padre Jacinto y de las formas de supervivencia del ser humano para satisfacer su ansia de inmortalidad, mismas que conducen ineludiblemente a la carne como única realidad del ser humano. En tercer lugar se terminan asentando algunos elementos que permiten afirmar por qué la agonía es agonía de la carne.

\section{VIDA, MUERTE Y AGONÍA}

Agonía, 'agonia', quiere decir lucha: "Agoniza el que vive luchando, luchando contra la vida misma. Y contra la muerte. Es la jaculatoria de santa Teresa de Jesús: «muero porque no muero»" (25). ${ }^{1}$ Por otro lado:

$$
\begin{aligned}
& \text { La vida es lucha y la solidaridad para la vida } \\
& \text { es lucha y se hace en la lucha. No me cansaré } \\
& \text { de repetir que lo que más nos une a los seres } \\
& \text { humanos unos con otros son nuestras discor- } \\
& \text { dias. Y lo que más le une a cada uno consigo } \\
& \text { mismo, lo que hace la unidad íntima de nues- } \\
& \text { tra vida, son nuestras discordias íntimas, las } \\
& \text { contradicciones interiores de nuestras discor- } \\
& \text { dias. Sólo se pone uno en paz consigo mismo, } \\
& \text { como Don Quijote, para morir (27). }
\end{aligned}
$$

Hasta aquí parecería suficiente lo dicho para caracterizar la agonía, pero no es así. A renglón seguido el filósofo añade lo siguiente, cosa que nos pone en camino, en palabras del mismo Unamuno, de aprehender nuestro asunto:

Y si esto es la vida física o corporal, la vida psíquica o espiritual es, a su vez, una lucha contra el eterno olvido. Y contra la historia. Porque la historia, que es el pensamiento de Dios en la tierra de los seres humanos, carece de última finalidad humana, camina al olvido, a la inconciencia. Y todo el esfuerzo del ser humano es dar finalidad humana a la historia,

1 Todas las citas pertenecientes a La agonía del cristianismo corresponden a Unamuno, 1998, por lo cual sólo se anota el número de página. 
finalidad sobrehumana, que diría Nietzsche, que fue el gran soñador del absurdo: el cristianismo social (27).

Lo primero que salta a la vista es que no es una única agonía la que el ser humano vive y padece, sino dos: la física o corporal y la psíquica o espiritual. Y son dos porque son dos vidas las del individuo: la terrena, la de la carne, y la celeste, la del espíritu. La primera lo pone en contacto consigo mismo y con los otros, es la vida de cada uno. La segunda lo vuelve hacia la historia de todos, que camina, se despliega sin cesar, sin tomar un respiro, al olvido y a la inconsciencia, a la nada. Esta vida lo vuelve hacia el pensamiento de Dios en la tierra, lo obliga a buscar una finalidad donde no la hay, es la vida de la sociedad, la cultura y los pueblos a los cuales pertenecemos. Ambas encuentran su fin último en la muerte, una muerte para dos vidas, ya sea al mismo tiempo, ya sea en diferente instante. Pero uno sólo es el tiempo, una la muerte y una la historia, por lo que esas dos vidas se nos manifiestan unidas. Una viene después de la otra, la sigue, de tal forma que son la misma. No son dos, insisto, sino una vista desde dos ámbitos distintos: el primero, el carnal, el de cada quien; el segundo, el espiritual, el de todos, pero también de cada uno. Y ésta continúa la primera. Si no son dos vidas, tampoco son dos agonías sino una, y no de dos seres humanos, que bien puede seguirse de admitir las dos vidas, sino de uno, del individuo de carne y hueso que agoniza entero, todo, completo, en cada ámbito.

Uno sólo es el sujeto, escindido en dos ámbitos: el espiritual y el carnal, vías de salvación y adquisición de la inmortalidad. Podemos decir que agoniza el que quiere morir y no puede, vive a pesar suyo; el que quiere vivir, pero sabe con total certeza que morirá; el que ve morir a quienes ama, queriendo que no sea así; el que sabe que su muerte es irremediable y por tanto tendrá que abandonar a su familia y amigos; el que no quiere ser olvidado y ve en la historia y el recuerdo su supervivencia y salvación; el que, como Borges afirma en su Elogio de la sombra (1974: 1014), sí quiere ser olvidado y morir con su cuerpo; el que, como san Pablo (Gal. 6: 17, 2; Cor. 4-10) siente que su cuerpo es un estorbo, un impedimento, una carga porque lleva en él las cicatrices de Jesús; el que duda de la inmortalidad del alma, de la resurrección de la carne; el que le apuesta a la inmortalidad del alma contra el cuerpo; el que espera la resurrección de la carne contra el alma; el que vive muriendo o muere viviendo; el que lucha, el que quiere creer y no puede, el que cree y no quiere.

La relación que guarda el cristianismo con la agonía es clara, por lo menos en el texto de Unamuno, donde se define, pues, como lucha:

Y el Cristo vino a traernos agonía, lucha, y no paz. Nos lo dijo él mismo: «No penséis que vine a meter paz en la tierra, no vine a meter paz, sino espada. Vine a separar al ser humano de su padre, y a la hija de su madre, y a la nuera de la suegra, y enemigos del ser humano los de su casa» (Mat. X: 34-37) (29).

Y esta lucha en otro ámbito, pero en el mismo ser humano, es la de la fe. Y la lucha de la fe es dudar, dudar es vivir. Fe que no lucha es fe muerta. Pero, ¿en qué consiste? Para Unamuno implica un combate, una dualidad:

Dubitare contiene la misma raíz, la del numeral duo, dos, que duellum, lucha. La duda, más la pascaliana, la duda agónica o polémica, que no la cartesiana o duda metódica, la duda de vida —vida es lucha-, y no de camino - método es camino-, supone la dualidad del combate (30-31).

Esta dualidad se hace patente en cada uno, en el que luchan el alma y el cuerpo por la primacía, en la relación entre seres humanos cuando uno quiere imponerse a otro, en la batalla que el individuo tiene con Dios, con la historia y el olvido. 
Ni siquiera la fe salva al hombre de luchar. De tal forma, la dialéctica de la agonía puede expresarse diciendo que des-nacer es morir y des-morir es nacer. No haber nacido es morir y no haber muerto es nacer. Lo que hay entre ambos momentos es vida, que es asimismo agonía, lucha contra y por la vida, contra y por la muerte: agonía del cristianismo. El cristiano, sin importar los matices de su fe y de su formación, es un agonista porque ser cristiano es hacerse Cristo. Lo sabía san Pablo, que sentía nacer y agonizar y morir en él a Cristo; también Adán, que pidió que se aliviase su soledad y después de calmada cayó con ella, dejando el paraíso, carne de su carne. Lo sabía Caín, que mató a su hermano movido por la envidia cuando la sintió y no pudo controlarla; también Abraham, al no poder negarse a la petición y encargo de Dios, cuando el hijo de la promesa fue requerido en sacrificio. Lo supo Job en el momento en el que se vio abandonado, lleno de llagas e ignorante ante las desgracias que le habían venido encima.

Lo sabían, lo sabemos nosotros, porque el cristianismo o la cristiandad, como Unamuno gusta llamarla, es un culto a un dios hombre que nació, agonizó, murió y resucitó de entre los muertos para transmitir su agonía a los creyentes: "La pasión de Cristo fue [es, digo yo] el centro del culto cristiano. Y como símbolo de esa pasión, la Eucaristía, el cuerpo de Cristo, que muere y es enterrado en cada uno de los que con él comulgan" (39). La pasión de un dios vivo es el centro del cristianismo. Dios vivo porque murió y resucitó, y por tanto, lo es de vivos y no de muertos. No se oculta tras las brumas de la especulación o tras las bambalinas de ese cielo inaccesible y abismal. Es un dios-ser humano, verdadero dios y verdadero hombre, que habita y padece con todos y cada uno de nosotros, que agoniza con y por el individuo, porque es hombre, carne.

Y esto quiere creer Unamuno. Quiere creer en la vida de Dios y no en la religión de la letra fundada por Pablo, que engendró a Agustín, que engendró a Calvino, que engendró a Jansenio, que engendraron a Kierkegaard. Religión encabezada por seres humanos de letras que sobreviven en ellas y con ellas llegan hasta nosotros (45). Pero el mismo Unamuno no escapa de su crítica. Fue engendrado ya sea por san Pablo, Agustín, Kierkegaard, o por todos, e introducido en su religión. Con esto se hizo un ser humano de letras que al no saber si su alma era inmortal o si la resurrección de los muertos acaecería, como su don Manuel, se dejó llevar por y con ellas a la contradicción que entrañan: la letra mata, pero el espíritu vivifica. La letra fija y lo fijo está muerto. La vida es movimiento, espíritu, lucha. Unamuno quiere creer, tener fe (acto agónico) en esta vida, en aquélla o en la de más allá, quiere existir, seguir viviendo, no morir en la letra. Anhela creer, y no puede, que su alma es inmortal, que resucitará, que sobrevivirá mediante sus libros, si bien esta forma de pervivir es una versión diferente de la inmortalidad del alma. Lo que hace de ésta una religión viva es que en ella se dan la vida y la lucha, de tal forma que tanto Unamuno como los otros son redimidos por la letra, la palabra que se hizo vida: "La letra se ve, pero la palabra se oye, y la fe entra por el oído" (68). La fe empieza por la carne y se afianza por ella. Es el oído de nuestro cuerpo el que oye la doctrina, es el ojo el que lee y consolida lo escuchado.

El problema, pues, es que el mismo cristianismo nos pone en la encrucijada de elegir una de dos formas de supervivencia. Si es así, si son dos las propuestas, preguntemos por medio de cuál nos salvaremos. ¿Por el cuerpo en la resurrección de la carne o por el espíritu mediante la inmortalidad del alma? ¿No son en el fondo contradictorias? (64). Sí, la muerte nos lo hace manifiesto. Cualquiera que elijamos, cualquiera que, y esto téngase en cuenta, intentemos imponer a otro, sea con argumentos o con la espada, se da en la medida en que buscamos convencernos puesto que queremos sobrevivir. 


\section{SuPERVIVENCIA Y AGONÍA DE LA CARNE}

El padre Jacinto agonizó, dudó y vivió en lucha. Su existencia, que bien puede ser la del mismo Unamuno o la de todos y cada uno de sus entes de ficción es, para los propósitos de este ensayo, el mejor ejemplo que el filósofo pudo darnos, por lo que no puedo sino recuperarlo. En el padre Jacinto, en su vida angustiosa y torturada encontramos la duda que caracteriza al cristiano, principio de su agonía. Vacila ante dos posibilidades contradictorias y ya anunciadas: la inmortalidad del alma y la resurrección de la carne.

El padre Jacinto abandona la Iglesia para casarse, tener hijos, perpetuarse en la carne, asegurar su resurrección. Lo hace para convertirse en padre. Y aquí en la paternidad está el fondo y la esencia de la tragedia humana, la agonía del cristianismo. La revelación de la paternidad, hecha por la virgen madre, acrecienta su preocupación por la vida histórica y civil, por el mundo y la fama, cosas ajenas al alma, si es que ésta es extraña al cuerpo y a lo que es de él. Pero si no lo es, y viendo la vida misma del padre Jacinto, cuya alma se caracteriza por un profundo misticismo, una acrecentada racionalidad y una lucha contra el egoísmo del cuerpo, tan odioso como el individual, caemos en la cuenta de que la inmortalidad del alma aparece también en la historia, el mundo y la fama. Pasar a la historia es enterrarse en ella. Hacerse famoso es dejar el alma aquí, ser recordado. De tal forma, son cosas del mundo tanto tener hijos y sobrevivir en la carne como preocuparse por la historia pensando en la supervivencia del alma. El padre Jacinto quiere quedarse en el mundo porque pertenece a él y no al reino de Dios. Cristo no constituyó una Iglesia, cosa de este mundo, sino que instituyó la eucaristía. Pero el sacramento del pan y el vino, que se comen y beben, también es cosa del mundo, porque el pan es carne y el vino, sangre. Esto se ve claramente en estas palabras, que el mismo Unamuno cita: "«Cuando mis huesos blanqueados estén en la tierra, cuando hayan perdido su forma y su polvo no tenga ya nombre entre los seres humanos, ¿qué es lo que quedará de mí en este mundo?»" (98).

El padre Jacinto se ve tentado por la carne, necesitado de un hijo en quien resucitar. Y es Mme. Mériman (antes de ella no había conocido mujer) la que lo convierte a la paternidad (que es del reino de este mundo). Porque la resurrección de la carne sólo adquiere sentido con la mujer. Y esta pasión furiosa, esta ansia de resurrección, nos revela la duda del padre Jacinto sobre la inmortalidad del alma, si es que la paternidad sólo es carnal. Pues si no lo es -y he aquí por qué es el fondo y la esencia de la agonía del cristianismo- hay también una paternidad espiritual, cosa que nos devuelve, y al padre Jacinto, a la consideración de sobrevivir en la historia mediante los hijos espirituales, y con ellos, a la posibilidad de tener una alma inmortal que trascienda la historia misma: "Y luchaban en él el padre y el ser humano civil hambriento de resurrección de la carne y de inmortalidad del alma y el cristiano, el solitario, el monje" (102). Lucha por ganar el pan de su mujer y sus hijos, pan de su carne. Lucha contra sí mismo con la duda en el fondo de su espíritu y la fe en el fondo de su alma: "No podía creer en la eternidad del Verbo, de la palabra, por la que se hizo todo, quería creer en la eternidad del hecho de la carne, acaso de la letra" (105). Quería sobrevivir en este mundo. Dudaba. Agonizaba en su duda, agonizaba la carne: "iÉste fue el ser humano, éste fue el padre, éste fue el cristiano en agonía del cristianismo!" (107). ¿Y la inmortalidad del alma?

Antes de responder esta pregunta se apuntará brevemente la relación que guardan los personajes de Unamuno con él y con el padre Jacinto. Se quiere mostrar que, aunque no haga del todo falta, pues es conocido por nosotros, todos los personajes de nuestro autor, incluido él mismo, ponen de relieve esta agonía que se refleja en sus ansias de inmortalidad, de sobrevivencia. 
Augusto Pérez, el personaje (o ente de ficción, como a Unamuno le gusta llamarle) de Niebla, expresa con toda claridad esta necesidad cuando al final de la 'nivola' grita a su creador: "iquiero vivir!” (1993:153), después de que éste le ha confesado su ineludible fallecimiento. Éste es, pues, el grito del ser humano vivo frente al conocimiento de la inminencia de la muerte. Cuando Meursault reflexiona sobre este hecho en el último capítulo de El extranjero, de Camus, no puede sino dar cuenta de que todos los hombres morirán. La única diferencia, apunta Meursault, es que él sabe cuándo. Lo mismo sucede con Augusto Pérez. Ambos personajes conocen la razón de su muerte: uno por el capricho de su creador, otro por el de la sociedad. A uno no le importa o parece no importarle, mientras que al otro le va la vida en ello, muere porque no muere, pero sabe que morirá queriendo que no pase, queriendo vivir. Su sobrevivencia, tal como nos muestra Unamuno, radica en la relectura del libro, en el recuerdo; sobrevivencia que asegura la del mismo Unamuno en el reino de este mundo, pero también en el alma y la memoria de los lectores.

Lo mismo sucede con la tía Tula al engendrar una hija espiritual en Manuela, hija de Ramiro y la sirvienta. Espiritual, sí, pero de carne, con la misma encomienda que la tía, con los mismos ojos y autoridad, a fin de cuentas sobrevivencia en este mundo (Unamuno, 1994). Joaquín Monegro, el agonista de Abel Sánchez, mediante sus memorias y la carta que deja a su hija quiere sobrevivir deshaciéndose de sí mismo, de su envidia. Busca ser otro en su hija, su yerno y nietos. Desea engendrar un hijo espiritual (cosa que no puede hacer de manera carnal) en el hijo de su rival para arrebatárselo, convertirse en su padre y así vivir en él (Unamuno, 1992). Manuel Bueno quiere pervivir en su pueblo porque no puede creer en la resurrección de los muertos y la vida futura. Él también engendra hijos espirituales en Ángela y Lázaro Carballido, asimismo, siente la agonía del cristianismo (Unamuno, 2000). ¿Y don Miguel de Unamuno? En su libro titulado
Cómo se hace una novela se muestra a sí mismo en el exilio como un ser humano agónico, preocupado por la situación de su patria, cosa de este mundo, y por su vida, una novela que cuando termine de ser escrita-leída acabará con la existencia de su autor (Unamuno, 2002). La enumeración de los personajes de Unamuno, él incluido, podría continuar, pero lo dicho es suficiente para mostrar mi argumento y, de alguna manera, adelantar una respuesta a la pregunta que líneas arriba he dejado en suspenso: iy la inmortalidad del alma?

Ya se ha abordado, o al menos apuntado, la diferencia y contradicción que hay entre las dos propuestas de sobrevivencia que nos encontramos en el cristianismo y que son propias de la agonía. Es momento de poner de relieve lo característico de cada una, de tal forma que pueda verse cómo ambas terminan remitiéndonos a la carne, y con ella, a la agonía del ser humano.

Lo primero que se expondrá es la inmortalidad del alma mediante dos consideraciones. La primera supone que el alma es una realidad aparte del cuerpo. La segunda la concibe como recuerdo, contenido de la memoria particular o pública. Quien mejor ilustra la primera posibilidad es Platón en uno de sus diálogos, el Fedón. El filósofo narra el último día de Sócrates, hombre para quien la filosofía era aprender a morir. ¿En qué consiste esto? En aprender y aprehender aquello que está por encima, más allá de la vida corporal; en aprender las ideas y entender (atender) el alma en su esencia, ajena a los lazos de la carne, liberada de las ataduras del cuerpo-cárcel. Lo anterior requiere por nuestra parte creer en ello. Y a esto apunta el Fedón, pues los argumentos esgrimidos son insuficientes para demostrar la inmortalidad del alma. Ya sea que se piense en la simpleza de ésta o en la anámnesis, es posible encontrar razonamientos en contra o la simple petición de principio que entrañan, sobre todo esta última. Tanto Hans-Georg Gadamer (1999) como Antonio Marino (2004) aluden a esto. La demostración de la inmortalidad del alma, 
suponiendo que ésta es de naturaleza diferente a la del cuerpo y, por tanto, una realidad distinta, puede venirse abajo fácilmente. Los juicios planteados no son bastantes, entonces, para demostrar su existencia. Lo único que resta es tener fe. Sócrates mismo se da cuenta de la dificultad de intentar demostrar lo indemostrable, por lo que al final apunta a ello sin dejar de lado un desprecio marcadísimo por el cuerpo y la creencia de que el alma es el ser humano en su totalidad. Si no fuese así, la sobrevivencia no valdría la pena, pues se estaría incompleto. De atenernos a lo anterior, como el padre Jacinto, tendríamos que elegir entre la fe en el alma inmortal y el mundo al que somos abandonados-arrojados como cuerpo. Pero si consideramos que el cuerpo y el mundo son las únicas realidades que conocemos y tenemos no nos queda opción: somos del mundo, el resto de las supervivencias serán y estarán en él.

Ser recordado es la segunda posibilidad de trascender la muerte 'como alma'. Supervivencia carnal, terrenal, que se divide en tres posibilidades. En primer lugar, se puede perdurar en el recuerdo de los otros, pero esto entraña dos problemas. Por un lado, iqué hacer cuando esos en los que hemos sobrevivido como recuerdo mueren?, por otro, ¿cómo saber que permaneceremos tal cual somos y hemos sido? Es decir, si el alma no es ajena al cuerpo la sobrevivencia es ya incompleta; además, si la memoria de los seres humanos cambia y se reinterpreta conforme el tiempo pasa no podemos asegurar que seremos recordados como fuimos. Se requiere el cuerpo. El segundo modo de subsistir es mediante los hijos espirituales que, visto con atención, constituye una versión más romántica de la primera. El tercer modo, el de muchos seres humanos, particularmente de los de letras, consiste en hacerlo en las obras, en los libros. Casi al final de su autobiografía Las palabras (2000), Jean-Paul Sartre afirma que al no poder creer en ningún modo de sobrevivencia, resurrección e inmortalidad del alma se hizo un cuerpo de cartón, pegamento y hojas, y un alma de letras, palabras y discursos. Ambos, alma y cuerpo, le permitirían vivir después de fallecer, perdurar en el mundo y en la historia. Pero si pensamos en la muerte de todos los seres humanos, en la aniquilación de la humanidad, y por tanto de su mundo y de su historia - una exageración, si se quiere, de la imaginaciónno podemos sino asumir que tal sobrevivencia y las anteriores no existirían. Otro problema, igual de extremo, radica en el actual énfasis que se pone en la tradición. En palabras de Borges (2003), todos los libros son partes de una sola obra escrita por un único espíritu o autor, de tal forma que las particularidades son accidentes sin importancia, por tanto, no vale la pena que sean tenidas en cuenta. Las vidas particulares de los seres humanos son nada comparadas con el acontecimiento del ser. El todo se privilegia. Esto ya es un límite enorme a la sobrevivencia de cada individuo. Lo que sí nos deja este pensamiento extremo es que cada ser humano es todos los demás, pues en cada uno la sobrevivencia del resto está en juego.

Si estas consideraciones sobre la inmortalidad del alma las pensamos en relación con, supongamos, una conmemoración de Unamuno o de cualquier otro individuo, los resultados no son nada gratos. Es decir, estaríamos recordando al poeta y filósofo español, ipero de qué forma? ¿Traeríamos a la memoria, sirva esto para ilustrar lo que he expuesto recién, a la persona Unamuno, a la realidad que fue, al ser humano de carne y hueso? La respuesta se nos hace obvia: no, porque no tenemos la posibilidad de verlo ni siquiera para que nos calle, con la característica voz aguda con la que llegaba a los cafés de España, por la cantidad de barbaridades que pueden decirse en su nombre. ¿Recordaríamos el evento Unamuno, la res histórica? No necesariamente. ¿Somos sus hijos espirituales?, ¿quién estaría dispuesto a asumir esto?

La otra forma de sobrevivencia es la de la carne, que se nos revela con el judaísmo y el 
cristianismo. Ésta se divide en dos. La primera es la paternidad o maternidad. Hombre y mujer se unen, abandonan a sus progenitores para ser una sola carne dadora de vida. En los hijos sobreviven y viven. Recordemos al padre Jacinto. Alfonso Reyes tiene un texto titulado "Metafísica de la cocinera" (2000) en el que cuenta cómo una mujer de España lograba que su guiso fuese sabroso siempre. El secreto, nos cuenta el literato mexicano, radica en que guardaba una taza del platillo del día anterior para echarlo en el del siguiente. El último guiso hecho conservaba algo del anterior y del primero. Lo mismo sucede con la paternidad. Una parte del primer ser humano permanece en el último, algo del padre perdura en el hijo. Pero es sólo una fracción, no todo. La sobrevivencia no es completa. Es decir, presenta los mismos problemas ya apuntados. Además, si como le pasó al padre Jacinto, los hijos fallecen antes que los padres, se lleva a cabo una ruptura en la cadena de sobrevivencia. Los hijos, pues, no son suficientes para trascender. La segunda forma de sobrevivencia en la carne es la resurrección de los muertos, que al igual que la inmortalidad del alma requiere de la fe, de querer creer en el Cristo resucitado. Lázaro volvió a la vida, pero murió de nuevo. Fe, otra vez. Duda y con ella lucha, es decir, agonía. Por otro lado:

Los seres humanos se atribuyen a sí mismos no sólo un valor contable, sino también una dignidad y una libertad de valor incalculable, cosas ambas que nunca han conferido al resto de las criaturas, se resisten a desaparecer con la desaparición de su estructura somática $[\ldots]$ se reconocen dotados [...] de una creatividad racional [...] de una creatividad estética $[\ldots]$ y de una creatividad ética (Ruiz de la Peña, 1988: 93).

La búsqueda de una explicación a estas tres constantes de la experiencia es el origen de la filosofía y obstinación del ser humano: creerse distinto de la bestia, del vegetal, de la simple cosa. Junto con ello vienen dos respuestas o formas de abordar el vacío, la inmortalidad del alma y la continuidad de la carne. Dicho vacío hace patente que esto, la vida, es mortal, una muerte vital, un des-nacer y un des-morir. La única verdad del ser humano es la muerte, que es el vacío y que llevamos a flor de piel. La diferencia entre conceptos se explica en las Confesiones de san Agustín. Ambos términos expresan con claridad la muerte como única verdad:

Un materialista francés [...] dijo que la vida es el conjunto de funciones que resisten a la muerte. Y así la definió agónica o, si se quiere, polémicamente. La vida era, pues, para él, la lucha, la agonía. Contra la muerte y también contra la verdad, contra la verdad de la muerte (26).

La vida es vida del cuerpo, de la carne. La muerte es muerte de aquél, de ésta. La única realidad es la carne.

\section{LA CARNE Y SU AGONÍA}

Lo expuesto hasta ahora nos permite considerar que la agonía de la que habla nuestro autor es la de la carne, cosa que no ha sido ni será demostrada, sino mostrada, tal y como sucede con la agonía del alma (el cogito y la interioridad nos sirven de ejemplos para esto), con el cuerpo y con la carne. No hay distinción entre ambos.

El cuerpo, la carne, se muestra, por lo menos así nos lo hace manifiesto san Agustín, como principio de verdad. Me atrevo a acudir a este autor porque ya se le mencionó y porque el mismo Unamuno cita sus ideas para enfrentarse al progreso y la modernidad en su texto "Sobre la europeización”. En Acerca de la vida feliz (1990), obra de san Agustín que continúa de cierta manera Contra los académicos, el filósofo propone como último argumento frente los escépticos el conocimiento indubitable de que el ser humano 
tiene cuerpo y vida. Nótese, dice vida y no alma. Los griegos pensaban esta última como ajena al cuerpo, un privilegio o rango del verdadero ser humano. Para san Agustín esto no es así. En la obra arriba citada aún no llega a la demostración del alma que da en Soliloquios. La definición que de individuo apunta este autor en su Acerca del orden responde a esta consideración: es, nos dice, un animal racional y mortal. Y la mortalidad que lo caracteriza le viene de ser cuerpo y vida, carne. Si nos atenemos a este hecho, la única realidad del ser humano es la del cuerpo. Pero, ¿qué es, cómo podemos entenderlo?

La carne originalmente designa (es) la de cualquier ser vivo, hombre o animal, y pasa a definir al ser viviente en su totalidad, emplazado en la percepción sensible de los demás seres. Es la manifestación exterior de la vitalidad orgánica. También se aplica a los animales como sustrato biológico común al hombre, ambos enraizados en un ámbito ontológico que los avecina. El ser humano como carne es un ser social que no se agota en la frontera de su piel, se prolonga en el tú próximo. Esto implica parentesco, el hecho de que todo individuo es siempre carne junto a carne, de forma que la del otro es también la propia en cierta medida. La expresión 'toda la carne' sirve para designar la totalidad solidaria de los individuos que componen la especie humana e incluso todos los seres vivientes. Lejos de connotar un principio de individuación, refiere un principio de comunión o sociabilidad. El individuo como carne sugiere los matices de debilidad física y moral, fragilidad y caducidad inherentes a la condición humana. La carne no es fuente de mal, como estipulan las antropologías dualistas, pero sí confirma la supremacía de Dios, de su espíritu, sobre toda carne (Ruiz de la Peña, 1988: 20-22).

$\mathrm{Si}$, como concluye san Agustín, el cuerpo es la única realidad del ser humano, podemos decir que no es una cosa entre las cosas. La experiencia puede convencernos de que no 'tenemos' sino que 'somos' un cuerpo. La carne constituye nuestro camino de acceso a las cosas, en palabras de
Husserl, nuestra apertura originaria al mundo, el saber consciente aunque prerreflexivo que tenemos sobre él: en verdad yo (nosotros) no pienso (pensamos) con el cuerpo, mediante o desde él, sino que pienso (pensamos) como cuerpo. No es el ojo el que ve, soy yo (somos nosotros) en cuanto cuerpo (Herrero, 2002). En su texto Acerca del maestro (1988), san Agustín apunta que tanto la historia como el lenguaje son del, por y para el cuerpo, de él parten y a él llegan (García Bacca, 1997).

Nietzsche estaría de acuerdo con esto. Para el alemán, el cuerpo, según lo expresa en su Zaratustra, es el sí-mismo del ser humano, origen creador del yo, del alma y de la verdad:

Que a él le debemos la invención del yo y de ese mundo inteligible de Platón, que a él le debemos ese afán incontrolado por pasar a la historia, por ser recordados [...] Porque él, al verse en el dolor, se dice, 'busquemos cómo aliviarlo', porque él, al verse en el placer, se dice, 'veamos cómo mantenerlo' (Nietzsche, 2004: 64-66).

Se sabe que Unamuno en una época despreció a Nietzsche, a quien acusó de seductor de la juventud y de ser el gran soñador del absurdo. Pero no olvidemos también que fue lector suyo y que sin duda hubo influencia de Nietzsche sobre el filósofo español. Para Foucault (2004), el cuerpo es la superficie de inscripción de los acontecimientos, lugar de disociación del yo, volumen en perpetuo desmoronamiento. Así, describió la relación cuerpo-historia de tal manera que el cuerpo se encuentra impregnado de historia y la historia arruina al cuerpo. Veíamos con san Agustín que del cuerpo surge la historia, por tanto podemos decir que es él el que se arruina a sí mismo siendo el depósito de la historia. Para el cristiano Tertuliano:

La carne es el quicio de la salvación, si el alma se hace totalmente de Dios, es la misma carne 
la que lo hace posible. La carne es lavada para que el alma sea limpia, la carne es ungida para que el alma sea consagrada, la carne es signada para que el alma sea robustecida, la carne es cubierta por la imposición de las manos para que el alma sea iluminada por el espíritu, la carne es nutrida con el cuerpo y la sangre de Cristo para que el alma se sacie de Dios (Tertuliano, en Ruiz de la Peña, 1988: 97).

Son muchos los elementos que hemos apuntado para mostrar qué es la carne y qué es el ser humano como cuerpo, pero poco hemos dicho de su agonía, tema que desde un principio nos propusimos tratar. Ahora es el momento de ahondar en el tema.

La agonía es lucha viva contra la muerte. El hombre es esencialmente carne y ésta constituye un principio de solidaridad, sociabilidad y cercanía entre los seres humanos; asimismo permite, dicho de esta forma, la empatía. Pensemos en el dolor y el sufrimiento, si bien no son lo mismo. A modo de ejemplo se presenta el caso de Ramiro y Rosa, que bien aplica a toda pareja o matrimonio. En La tía Tula, Unamuno reflexiona en boca de Ramiro, sin decirlo, sobre la sentencia bíblica que ya apuntamos: "por tanto el hombre dejará a su padre y a su madre y se unirá a su mujer, y serán una sola carne" (Gn. 2: 24). Ramiro, recién casado, siente cómo la sangre le hierve y el cuerpo le cosquillea al estar cerca de su esposa. Conforme el tiempo pasa estas sensaciones dejan lugar a otras. Tocar a Rosa, dice Ramiro, es tanto como tocarse a sí mismo. Y si a ella le pasara algo, desde una fractura hasta una amputación, él mismo sentiría que es una parte de él la que se ha fracturado o amputado. He aquí la agonía de la carne, carne solidaria, empática. El dolor individual, del cuerpo, muestra esta agonía. La compasión sólo es posible si se asume el ser humano como carne.

La lucha de la carne contra la muerte se muestra fundamentalmente en dos circunstancias. La primera es el absurdo del mundo. A menos que el ser humano crea el relato del progreso o la existencia de un mundo ajeno a éste, sus actos carecen de sentido. La modernidad constituye un caso paradigmático de lo anterior al incluir el cuerpo en el ámbito de la naturaleza con la esperanza de dominarlo, apuntando siempre a la sobrevivencia espiritual. La modernidad quita todo sentido al cuerpo, aun dándoselo. Es decir, lo que se conoce como liberación de las pasiones no es sino el dominio total sobre el cuerpo, despojado de sí mismo; no es propia ni libre, está sujeta a los designios del espíritu. Esta es la muerte de la carne, de su voluntad, de su lucha, de su vida.

La segunda circunstancia es la de la muerte, fin de la vida. Aquí pueden distinguirse tres aspectos. En primer lugar, la muerte muestra el sin-sentido del mundo y de la historia. Unamuno ya lo decía cuando veía que el ser humano se empeña por dar sentido a lo que no lo tiene. En segundo lugar está la muerte propia, expuesta a lo largo de este ensayo. La carne es la que agoniza cuando sabe que es finita, que morirá. Por último, está la muerte de los otros. El ser humano-carne no sabe qué hacer frente al cadáver, comida de gusanos. Ya Aristóteles daba cuenta de ello. El cadáver no es lo que fue, no es carne viva. Calla, se mantiene en silencio haciendo patente la muerte. Y el vivo intenta, sin lograrlo, darle sentido. Con este intento lucha contra la muerte, de tal forma que puede afirmar, aunque no al modo de santa Teresa: 'muero porque no muero'. Lo que sería más correcto decir es 'muero porque muero'. La lucha, la agonía, es de la carne que se quiere viva, pero que no puede evitar la muerte.

El cristianismo tiene muy presente lo anterior. La agonía del cristiano se hace patente en cada instante, pues en todo momento se está jugando la vida. Vida de solitario, vida en soledad. Y esta es la tragedia, el fatalismo. Calderón de la Barca, cristiano y agonista español, en su obra El gran teatro del mundo (1999) hace del ser humano un actor, y con ello muestra la agonía en la que vive, la tragedia a la que está sujeto. 
Para Calderón de la Barca, el papel que desempeñamos en esta puesta en escena que es el mundo está determinado de antemano. Hasta podríamos decir que la máscara que utilizamos es de carne. El alma se reviste con el cuerpo durante la representación para al final, sea condenada o salvada, despojarse de él. En su novela La máscara de carne (1973), Van der Meersch asume la escisión entre alma y cuerpo para poder decir que hay un alma de mujer o de hombre depositada en el cuerpo de un varón o mujer (no desarrollamos suficientemente esta tesis, pues si bien se apuntaron algunas pistas, explicar la homosexualidad se nos escapa, dejándonos en la incertidumbre total). Si no hay separación entre alma y cuerpo, este último no puede ser máscara, la representación teatral seguiría llevándose a cabo, pero la salvación y la condena serían de la carne y no del espíritu. El Cristo que con su encarnación cumplió cabalmente que el ser humano fuese a imagen y semejanza de Dios deja al individuo en la encrucijada de optar por creer que puede sobrevivir como alma o como carne. Pero ambas creencias se contradicen.

Podríamos afirmar que todos somos Cristo y que, como él, vivimos en la lucha, esgrimimos la espada y no la paz. Téngase en cuenta la noche en el huerto de los olivos y la crucifixión en la que Cristo gritó: "Dios mío, ipor qué me has abandonado?” (Mt. 27: 46). Así, abandonados de Dios, vivimos, somos carne luchando por sobrevivir, combatiendo contra el dolor y contra el sufrimiento.

\section{ConcLusión}

La agonía del cristiano, que es la de cada ser humano, constituye la lucha del cristianismo todo por la inmortalidad y la supervivencia. Esta batalla la libran la carne y el espíritu, el alma y el cuerpo. El ser humano, el de carne y hueso, ha buscado la manera de sobrevivir, por más que no se haya demostrado que esto sea posible. Una solución, la judía, propone la supervivencia de la carne, ya sea en la paternidad o en la resurrección; la otra, la griega, le apuesta al alma, a su inmortalidad, despreciando el cuerpo, queriendo deshacerse de él.

Se propuso en este ensayo mostrar que la lucha que caracteriza al ser humano concreto es agonía de la carne que se quiere a sí misma cuerpo vivo, pero que encuentra en la muerte un obstáculo infranqueable para ver cumplido su deseo. En la revisión hecha, de la mano de don Miguel de Unamuno y del padre Jacinto se exploraron las alternativas y dificultades para alcanzar la inmortalidad, lo cual nos permitió establecer la imposibilidad de demostrarla. Se concluyó que el deseo o anhelo de sobrevivir caracterizan al ser humano, el cual, en tanto cuerpo, agoniza por no poder salir victorioso de la lucha.

Unamuno, ser humano de carne y hueso, que quería ser salvo pero sin dejar de ser él mismo, sintió profundamente esta agonía. Él mismo lo dice, comparándose con el padre Jacinto: "Lo que voy a exponer aquí, lector, es mi agonía, mi lucha por el cristianismo, la agonía del cristianismo en mí, su muerte y su resurrección en cada momento de mi vida íntima” (25). Unamuno sintió profundamente la agonía del ser humano que es carne, y por ella, finita de suyo, le viene la condena que consiste en que el anhelo de infinitud no pasa de ser un deseo.

En tanto carne de este mundo todos agonizamos, por más que se huya, sea de la manera que sea, incluso por la vía del dolor. 


\section{REFERENCIAS}

Borges, Jorge Luis (1974), "Elogio de la sombra”, en Obras completas 1923-1972, Buenos Aires, Emecé.

Borges, Jorge Luis (2003), "El libro", en Borges oral, Madrid, Alianza.

Calderón de la Barca, Pedro (1999), El gran teatro del mundo, México, FCE

Foucault, Michel (2004), Nietzsche, la genealogía, la historia, Valencia, Pre-textos.

Gadamer, Hans-George (1999), El inicio de la filosofía occidental, Barcelona, Paidós.

García Bacca, Juan David (1997), Antropología filosófica contemporánea, Barcelona, Anthropos.

Herrero, D. (2002), "Qué es fenomenología”, Lección inaugural del Año Académico, Facultad de Filosofía de la Universidad San Buenaventura.

Marino, Antonio (2004), Senderos dialógicos entre antiguos y modernos, México, UNAM.

Nietzsche, Friedrich (2004), Así habló Zaratustra, Madrid, Alianza.

Reyes, Alfonso (2000), "Metafísica de la cocinera", en Debate entre el vino y la cerveza, México, FCE, pp. 7-9.

Ruiz de la Peña, Juan Luis (1988), Imagen de Dios. Antropología teológica fundamental, Santander, Sal Terrae.

San Agustín (1988), Acerca del maestro, México, SEP.

San Agustín (1990), Acerca de la vida feliz, Buenos Aires, Lumen.

Sartre, Jean-Paul (2000), Las palabras, Buenos Aires, Losada.

Unamuno, Miguel de (1992), Abel Sánchez, México, Espasa Calpe.

Unamuno, Miguel de (1993), Niebla, México, Espasa Calpe.

Unamuno, Miguel de (1994), La tía Tula, México, Espasa Calpe.

Unamuno, Miguel de (1998), La agonía del cristianismo, Madrid, Alianza.

Unamuno, Miguel de (2000), San Manuel Bueno, mártir, Madrid, Cátedra.

Unamuno, Miguel de (2002), Cómo se hace una novela, México, Porrúa.

Unamuno, Miguel de (2003), Del sentimiento trágico de la vida, Madrid, Alianza.

Van der Meersch, Maxence (1973), La máscara de came, Barcelona, Plaza y Janés.

JuAN Granados ValdÉz. Licenciado en Filosofía y Maestro en Arte Contemporáneo y Sociedad por la Universidad Autónoma de Querétaro (UAQ), México. Doctor en Artes por la Universidad de Guanajuato (UDG), México. Coordinador del Doctorado en Artes de la Facultad de Bellas Artes de la UAQ. Sus temas de interés versan sobre estética, filosofía de la religión, ética y teoría del arte. Entre sus últimas publicaciones se encuentran: "El repositorio digital como posibilidad de preservación de la cultura artística" (RIDE. Revista Iberoamericana para la Investigación y el Desarrollo Educativo, vol. 9, núm. 18); "Evaluación de algunas propuestas consideradas como de ética contemporánea" (Konvergencias. Filosofía y Culturas en Diálogos, núm. 26); y "Preliminares en torno a una teoría del juego en San Agustín" (Reflexiones Marginales. Saberes de Frontera, vol. 7, núm. 45). 